\title{
PRINSIP KESANTUNAN BERBAHASA SISWA
}

\author{
Melia \\ IKIP PGRI Pontianak \\ melygautama@gmail.com
}

\begin{abstract}
Abstrak
Penelitian ini mendeskripsikan prinsip kesatunan berbahasa yang terdapat pada siswa di SMP Negeri 1 Sungai Raya dengan kajian pragmatik. Tujuan dalam penelitian ini adalah untuk mendeskripsikan maksim kebijaksanaan, kedermawanan, penghargaan, kesderhanaan, pemufakatan dan kesimpatian. Penelitian ini menggunakan metode penelitian deskriptif kualitatif yang menguraikan dan menyajikan data-data yang diperoleh secara faktual dan akurat. Teknik pengumpulan data ini menggunakan teknik simak bebas libat cakap dan teknik catat dan alatnya menggunakan alat rekam dan catatan lapangan. Hasil penelitian menunjukan bahwa prinsip kesantunan berbahasa pada siswa SMP Negeri 1 Sungai Raya terdapat kesantunan pada saat bertutur.
\end{abstract}

Kata Kunci: pragmatik, prinsip kesantunan, siswa

\begin{abstract}
This study describes the principle of language obedience found in students in SMP Negeri 1 Sungai Raya with a pragmatic study. The purpose of this study is to describe the maxim of wisdom, generosity, appreciation, simplicity, consensus and conclusions. This study uses descriptive qualitative research methods that describe and present data obtained in factual and accurate. This data collection technique uses skillful free listening techniques and note-taking techniques and tools using record tools and field notes. The results of the study showed that the principle of politeness of language in SMP Negeri 1 Sungai Raya students was politeness when speaking.
\end{abstract}

Keywords: pragmatics, politeness principles, students

\section{PENDAHULUAN}

Penelitian kebahasaan merupakan sebuah bidang bahasa yang mengkaji bahasa berserta konteksnya, disebut pragmatik. Pragmatik adalah cabang ilmu bahasa yang mempelajari struktur bahasa secara eksternal, yaitu berkaitan dengan bagaimana suatu bahasa itu digunakan dalam komunikasi. Kajian pragmatik membahas sebuah penggunaan bahasa di dalam komunikasi yang pada dasarnya di tentukan oleh konteks. Pragmatik juga membahas prinsip kesantunan mengenai maksim kebijaksanaa, maksim kedermawanan, maksim penghargaan, maksim keserderhanaan, maksim permufakatan dan maksim kesimpatian.

Prinsip kesantunan menurut Leech bahwa dalam berkomunikasi antara penutur dan mitra tutur perlu adanya sopan santun yang menunjukkan suatu kearifan, kedermawaan, pujian, kerendahan hati, kesepakatan, dan tumbuhnya rasa simpati, sehingga timbul suatu sopan santun atau tatakrama dalam berkomunikasi, 
saling menghormati, tidak merugikan orang lain dan orang lain merasa diuntungkan. Menurut Rahardi (2005: 35) mengemukakan bahwa "penelitian kesantunan mengkaji penggunaan bahasa (language use) dalam suatu masyarakat bahasa tertentu. Masyarakat tuturan yang dimaksud adalah masyarakat dengan aneka latar belakang situasi sosial dan budaya yang mewadahinya.

Adapun prinsip adalah pandangan atau acuan yang menjadi panduan seseorang dalam bertindak, melakukan sesuatu, serta berhubungan dengan orang lain. kesantunan berasal dari kata santun yang berarti baik budi bahasanya dan tingkah lakunya. kesantunan adalah tatacara bertindak atau gerak-gerik ketika menghadapi sesuatu dalam situasi tertentu. Adapun yang dikaji dalam penelitian kesantunan adalah segi maksud dan fungsi tuturan, dalam hal ini maksud dan fungsi tuturan imperative bahasa Indonesia. Kesantunan memperlihatkan sikap yang mengandung nilai sopan santun dalam berhubungan sosial. Ketika seseorang dikatakan santun, maka dalam diri seseorang itu tergambar nilai sopan santun yang berlaku secara baik di masyarakat tempat seseorang itu mengambil bagian sebagai anggotanya.

\section{METODE}

Metode penelitian yang digunakan dalam penelitian ini adalah metode deskriptif yaitu untuk mendeskripsikan tindak tutur guru. Menurut Zuldafrial (2009:22) menjelaskan "Penelitian deskriptif adalah suatu metode yang digunakan dalam memecahkan masalah penelitian dengan cara menggambarkan atau melukiskan keadaan subjek atau objek penelitian pada saat sekarang berdasarkan fakta-fakta yang tampak atau sebagaimana adanya”. Bentuk penelitian yang digunakan dalam penelitian ini adalah bentuk kualitatif yaitu data penelitian yang berupa kata-kata dari tuturan guru terhadap anak autis. Menurut Sujarweni (2014:89) menjelaskan "Data merupakan sekumpulan informasi yang diperoleh dari lapangan dan digunakan untuk bahan penelitian”.

Dengan demikian, laporan penelitian akan berisi kutipan-kutipan data untuk memberi gambaran berdasarkan fakta-fakta yang tampak atau sebagaimana adanya. Metode deskriptif ini juga dianggap sesuai dengan penelitian ini, karena penelitian ini bertujuan untuk mendeskripsikan serta memberikan gambaran secara objektif 
tentang prinsip kesantunan berbahasa pada siswa SMP Negeri 1 Sungai Raya dikarenakan siswa SMP adalah masa-masa di mana siswa masih dalam masa penjajakan atau yang biasa disebut masa labil. Dalam hal inilah siswa SMP yang dijadikan objek dikarenakan siswa SMP jika berbicara mengikuti lingkungan, baik lingkungan keluarga maupun lingkungan pertemanannya. Seperti yang telah dijelaskan oleh Darmadi (2011:7) "Penelitian deskriptif berkaitan dengan pengumpulan data untuk memberikan gambaran atau penegasan suatu konsep gejala, juga menjawab pertanyaan-pertanyaan sehubung dengan suatu subjek penelitian pada saat ini, minsalnya sikap atau pendapat terhadap individu, organisasi, dan sebagainya". Data yang diperlukan merupakan data yang berkaitan dengan prinsip kesantunan berbahasa pada siswa SMP Negeri 1 Sungai Raya. Seperti yang dijelaskan oleh Bogdan dan Taylor (Sujarweni 2014: 19) menalkan bahwa, "Penelitian kualitatif adalah salah satu prosedur penelitian yang menghasilkan data deskriptif berupa ucapan atau tulisan dan prilaku orangorang yang diamati”.

\section{HASIL DAN PEMBAHASAN}

\section{Prinsip Kesantunan Berbahasa Pada Siswa SMP Negeri 1 Sungai Raya}

\section{Prinsip Kesantunan Pada Saat Siswa Bertutur}

Kesantunan adalah sikap rendah hati, tenggang rasa dan menjaga perasaan lawan berbicara, dan memberi penghargaan atau menghormati, orang yang diajak bicara dan juga merupakan aturan perilaku sosial yang ditetapkan bersama-sama oleh masyarakat yang menetap disuatu lingkungan, oleh karena itu kesantunan juga disebut sebagai tata karma. Menurut Leech, Penelope Brown dan Stephen Levinson (Sulistyo, 2013:26) "Kesantunan atau kesopanan adalah perlakuan suatu konsep tegas yang sopan yang terdapat di budaya atau suatu masyarakat. Khususnya dalam bahasa sopan santun atau tatakarama berbahasa adalah menghargai dan menghormati pesapa. Sulistyo, (2013:27) maksim kebijaksanaan, maksim kemurahan atau maksim kedermawanan, maksim penerimaan atau pujian, atau penghargaan, maksim kerendahan hati atau keserderhanaan, maksim kecocokan atau permufakatan, dan maksim kesimpatian”. Prinsip kesantunan terbagi menjadi enam maksim di dalam 
penelitian ini dituturkan secara langsung oleh siswa kepada temannya maupun kepada guru pada saat proses pembelajaran belangsung maupun di luar jam pelajaran pada siswa Smp Negeri 1 Saungai Raya.

\section{a. Maksim Kebijaksanaan}

Prinsip kesantunan ini merupakan satu diantara kajian pragmatik yang menelaah tentang prinsip kesantunan menurut Leech memiliki beberapa jenis yang akan dijelaskan sebagai berikut. Berdasarkan pendapat Wijana (2011: 137) menjelaskan bahwa "Maksim kedermawanan minimalkan kerugian orang lain dan maksimalkan keuntungan orang lain”.

\section{Data [1]}

Siswa (Kia) : "Silahkan kamu saja yang bertanya terlebih dahulu Nisa, nanti setelah kamu saya yang akan bertanya".

Tuturan di atas dituturkan oleh siswa yang bernama Kia yang mempersilahkan kepada siswa yang bernama Nisa untuk bertanya terlebih dahulu pada saat berdiskusi kelompok di kelas. Tuturan yang disampaikan oleh siswa yang bernama Kia terlihat berusaha memaksimalkan keuntungan kepada siswa yang bernama Nisa dengan cara mempersilahkan rekan tuturnya untuk bertanya terlebih dahulu. Tuturan Kia terindikasi mematuhi maksim kebijaksanaan, karena telah mengurangi keuntungan diri sendiri dan memaksimalkan keuntungan pihak lain. Tuturan yang menyatakan bahwa siswa Kia mematuhi maksim kebijaksanaan adalah "Silahkan kamu saja yang bertanya" kata "Silahkan" menyatakan maksim kebijaksanaan karena telah memaksimal keuntungan kepada Nisa untuk mempersilahkan bertanya duluan. Tuturan itu di sampaikan kepada siswa yang bernama Nisa meskipun siswa yang bernama Kia dalam waktu bersamaan lebih dulu mengacungkan tangan namun siswa yang bernama Kia dengan senang hati mempersilahkan kepada rekan tuturnya dengan maksud agar siswa yang bernama Nisa merasa senang dan lebih diuntungkan.

\section{Data [2]}

Guru (Siskawati) : : :Kembali ke kursimu, kamu pinjam pensil warna ibu saja". 
Pada data di atas terjadi pertuturan antara guru dan siswa yang bernama Siskawati dan Viska, guru yang bernama Siskawati memberi pinjaman pensil warna kepada siswanya yang bernama Viska agar tidak duduk berpindahpindah. Dalam tuturan ini, tampak bahwa guru Siskawati memberikan keuntungannya kepada siswa yang bernama Viska. Adapun kalimat yang terindikasi mematuhi maksim kebijaksanaan adalah "Kamu pinjam pensil warna ibu saja" kata "Pinjam" menyatakan maksim kebijaksanaan karena telah memaksimal keuntungan kepada Viska untuk meminjamkan pensil.

\section{b. Maksim kedermawanan}

Berbeda dengan maksim kedermawaan, maksim kedermawaan adalah sebuah perlakuan yang dilakukan untuk membuat orang lain dapat menghormati orang dengan perlakuan penutur terhadap lawan tutur. Wijana (2011:137) memaparkan bahwa "Maksim kemurahhatian minimalkan keuntungan diri sendiri dan maksimalkan kerugian diri sendiri”.

\section{Data [1]}

Gita : Saya saja bu, yang maju kedepan

Berdasarkan kutipan di atas dituturkan oleh seorang guru kepada siswa dalam ruang kelas pada saat proses pembelajaran berlangsung. Saat itu, guru tersebut menanyakan kepada siswanya siapakah yang bersedia menjawab soalnya tersebut kemudian guru Siskawati menyuruh Tia maju kedepan. Permintaan guru tersebut mendapatkan tolakan dari siswanya yang bernama Tia dan pada saat itu juga ia mendapatkan tawaran dari siswa lainnya yang bernama Gita. Kutipan di atas tampak dengan sangat jelas bahwa apa yang dituturkan oleh siswa yang bernama Gita berusaha memaksimalkan keuntungan pihak temannya yang bernama Tia dengan cara menambahkan beban bagi dirinya sendiri. Hal ini dengan cara menawarkan diri untuk menjawab soal di depan. Kutipan yang menyatakan bahwa siswa yang bernama Gita mematuhi maksim kedermawanan ialah "Saya saja bu, yang maju kedepan". Kutipan "Saya saja bu yang maju kedepan" menyatakan maksim kedermawanan karena tuturan tersebut telah mengurangi keuntungan diri sendiri dan tambahi pengorbanan diri sendiri 
yaitu manawarkan diri sendiri untuk menjawab pertanyaan dari guru yang seharusnya si Tia yang menjawab pertanyaannya.

\section{Data [2]}

Kia : Ria sini, biar aku saja yang membawa buku tugasnya?

Pada data di atas dituturkan oleh seorang siswa yang bernama Kia kepada temannya yang bernama Ria yang juga seorang siswa dalam ruangan kelas yang sama. Tuturan ini tampak sangat jelas bahwa apa yang dituturkan oleh Kia sungguh maksimalkan keuntungan pihak temannya yang benama Ria dengan cara menambahkan beban bagi dirinya sendiri. Hal itu dilakukan dengan cara menawarkan bantuan untuk membawakan buku tugas. Pemaksimal keuntungan pihak lain dengan cara menambahkan beban bagi dirinya sendiri terlihat dari tuturan siswa bernama Kia yaitu: "Ria sini, biar aku saja yang membawa buku tugasnya". Tuturan itu disampaikan kepada Ria dengan maksud bahwa Kia berusaha untuk meringankan beban temannya tersebut. Sekalipun sebenarnya, bisa saja Kia tidak mau menambah beban bagi dirinya, namun karena siswa yang bernama Kia tersebut berusaha memaksimalkan keuntugan pihak temannya yang bernama Ria, Kia pun langsung membawakan buku tersebut menuju ke kantor.

\section{c. Maksim Penghargaan}

Berbeda dengan maksim penghargaan, mengurangi cacian kepada orang lain dan menambah pujian kepada orang lain adalah bentuk penghargaan kepada orang lain. Berdasarkan pendapat Wijana (2011: 137) memaparkan bahwa "Maksim penerimaan minimalkan ketidakhormatan pada orang lain dan maksimal rasa hormat pada orang lain".

\section{Data [1]}

Kia : Tia cara membaca puisi mu sudah bagus, dan intonasi kamu pun $\underline{\text { sudah bagus dan kelancaran dalam membacakan puisi kamu pun }}$ $\underline{\text { sudah sangat jelas }}$ 
Pada tuturan di atas dituturkan oleh siswa yang bernama Kia kepada temannya yang bernama Tia yang sedang duduk di anak tangga, Kia meminta kepada Tia untuk latihan membaca puisi di depan kelas. Saat itu juga, ia meminta kepada Tia untuk mempratikkan membaca puisi. Setelah selesai siswa yang bernama Tia membaca puisi, si Kia pun menanggapi dengan sangat baik dengan cara memuji temannya. Tuturan di atas terlihat sangat jelas bahwa apa yang diberitahukan oleh Kia berusaha memberikan penghargaan kepada temannya yang bernama Tia. Tuturan ini dimaksud dengan maksim penghargaan yang dilakukan dengan cara memuji hasil latihan baca puisi temannya tersebut tampak pada tuturan Kia yaitu "Tia cara membaca puisi mu sudah bagus, dan intonasi kamu pun sudah bagus, indah dan kelancaran dalam membacakan puisi kamu pun sudah sangat jelas". Walaupun sebenarnya, bisa saja si Kia tidak memberikan penghargaan bahkan tidak memujinya. Tuturan itu bermaksud agar si Tia merasa senang dan tidak merasa sakit hati.

\section{Data [2]}

Guru (Siskawati)

:Iya Viska(nama sebenarnya), bagus sekali kamu $\underline{\text { sudah memahami dari alur cerita tersebut, kamu }}$ bisa maju kedepan untuk mendapat hadiah ini.

Berdasarkan data di atas dituturkan oleh seorang guru kepada siswanya dalam ruang kelas pada saat jam pelajaran berlangsung. Guru meminta salah salah satu siswa untuk menyimpulkan cerita dari video yang ditonton bersama-sama di dalam kelas. Seorang siswa yang bernama Viska pun menyimpulkan dari cerita tersebut, namun selesai Viska menyimpulkan dari hasil yang dia tonton, guru Siskawati pun memberikan pujian, terhadap Viska tentang vidio yang telah siswanya simpulkan. Tuturan di atas tampak sangat jelas bahwa apa yang diberitahukan guru Siskawati berusaha memberikan penghargaan kepada siswanya bernama Viska. Hal itu dilakukan dengan cara memujikan jawaban dari Viska. Penghargaan yang dilakukan dengan cara memuji hasil dari jawaban Viska tersebut tampak pada tuturan guru (Siskawati) yakni: "Iya Viska, bagus sekali kamu sudah 
memahami dari alur cerita tersebut, kamu bisa maju kedepan untuk mendapat hadiah ini. Walaupun sebenarnya, bisa saja guru yang bernama Siskawati tidak memberikan penghargaan bahkan tidak memujinya. Tuturan itu disampaikan dengan maksud agar siswanya merasa senang dan tidak sakit hati.

\section{d. Maksim Keserderhanaan}

Berbeda dengan maksim keserdahaan atau maksim hati adalah sebuah situasi tutur yang mengurangi pujian pada diri sendiri. Bersikap rendah hati dan tidak tinggi diri adalah wujud keserderhanaan diri. Wijana (2011:137) mengemukakan bahwa "maksim kerendahan hati minimalkan rasa hormat pada diri sendiri dan manimalkan rasa tidak hormat pada diri sendiri”.

\section{Data [1]}

Lia: Biasa aja kok, ini jelek pun. Kalau tulisan mu yang bagus si iya

Berdasarkan tuturan di atas dituturkan oleh Lia kepada temannya yang bernama Mia di ruang kelas pada saat jam Istirahat. Saat itu, Lia berjalan menuju kearah Mia dan ingin bercerita tentang masalah tugas yang barusan diberikan oleh gurunya, namun tidak sengaja Lia melihat tulisan Mia yang bagus. Saat itu juga, siswa yang bernama Mia memberikan pujian kepada temannya bernama Lia. Lia merasakan bahwa dirinya mendapatkan pujian dari temannya itu Lia pun langsung merendahkan diri. Tuturan di atas sudah sangat jelas bahwa apa yang dituturkan oleh Lia terhadap temannya yang bernama Mia sudah merendahkan diri. Hal itu dilakukan dengan cara mengurangi pujian pada diri sendiri. Sikap rendah hati yang dilakukan dengan cara mengurangi pujian terhadap pada diri sendiri tampak pada tuturan siswa yang bernama Lia yakni” Biasa aja kok, ini jelek pun. Kalau tulisan kamu yang bagus si iya". Tuturan itu sengaja di ucapkan dengan maksud agar ia tidak dikatakan sebagai orang yang sombong. Tuturan di atas sudah mematuhi maksim keserderhanaan, karena telah kurangi pujian pada diri sendiri dan tambahi cacian pada diri sendiri. Data [2] 
Kia: Tidak kok kak, ini pulpen murah kok

Berdasarkan kutipan di atas di tuturkan oleh Kia kepada anak kelas 2 yang bernama Maria pada saat di depan kelas. Pada saat itu Maria sedang buru-buru ingin mengisi absen yang diberikan oleh gurunya. Saat itu juga siswa yang bernama Ria memberikan pinjaman pulpennya, kepada Maria. Saat itu juga Maria memuji pulpen si Ria bahwa tintanya bagus. Lia merasa dirinya dipuji oleh Maria, Lia pun langsung merendahkan dirinya. Tuturan di atas terlihat sangat jelas bahwa apa yang dituturkan oleh siswa bernama Kia terhadap temannya yang bernama Maria sungguh bersikap rendah hati. Hal itu, dilakukan dengan cara mengurangi pujian terhadap dirinya sendiri. Sikap rendah hati yang dilakukan dengan cara mengurangi pujian terhadap dirinya sendiri tampak pada tuturan siswa yang bernama Kia yakni "Tidak kok kak, ini pulpen murah kok". Tuturan itu bertujuan agar ia tidak dikatakan sebagai orang yang sombong atau tidak santun.

\section{e. Maksim Permufakatan}

Berbeda dengan maksim permufakatan maksim ini menggariskan kecocokan diantara mereka, dan meminimalkan ketidak cocokan diantara mereka. Apabila terdapat kecocokan atau pemufakatan antara diri penutur dan mitra tutur dalam kegiatan bertutur, maka masingmasing dari mereka dapat dikatan santun dalam berbahasa. Wijana (2011: 137) menyatakan bahwa "Maksim kecocokan minimalkan ketidak cocokan dengan orang lain dan maksimalkan kecocokan dengan orang lain".

\section{Data [1]}

\section{Kia : Ayo lah, aku temanin}

Berdasarkan tuturan di atas dituturkan oleh siswa yang bernama Viska kepada temannya yang bernama Kia. Pada saat itu Kia sedang asik bercerita dengan temannya yang lain, tiba-tiba Viska memanggil Kia untuk pergi dengannya. Saat itu Kia pun mau mengikuti Viska dan menemaninya untuk pergi kebelakang. Tuturan di atas sangat jelas bahwa 
Kia terindikasi mematuhi maksim permufakatan, karena telah mengurangi ketidak sesuaian antar diri sendiri dengan orang lain dan meningkatkan persesuaian antar diri sendiri dengan orang lain. Tuturan yang menyatakan bahwa Kia mematuhi maksim permufakatan ialah "Ayo lah, aku temanin" tuturan "Ayo lah, aku temanin" menyatakan maksim permufakatan karena tuturan tersebut telah meningkatkan persesuaian antar diri sendiri dengan orang lain. Tuturan itu disampaikan kepada temannya yang bernama Viska dengan maksud bahwa ia menerima jawaban yang sangat tepat agar temannya yang bernama Viska tidak tersinggung.

\section{Data[2]}

Kia : Oh, Rian tunggu sebentar Pak, saya panggilkan dulu orangnya

Data di atas dituturkan oleh siswa yang bernama Kia kepada temannya pada saat jam istirahat. Pada saat itu seorang guru yang bernama bapak Aris meminta kepada siswanya untuk memanggil temannya yang bernama Rian, Kia pun langsung segera mencari Rian. Tuturan di atas terindikasi mematuhi maksim permufakatan, karena telah mengurangi ketidak sesuaian antar diri sendiri dengan orang lain dan meningkatkan persesuaian antar diri sendiri dengan orang lain. Tuturan yang menyatakan bahwa Kia mematuhi maksim permufakatan ialah "Oh Rian tunggu sebentar pak, saya panggilkan dulu orangnya". Tuturan di atas sengaja disampaikan dengan maksud bahwa agar dirinya kepada guru Aris mendapatkan persesuaian yang tepat dari jawabannya tersebut.

\section{f. Maksim Kesimpatian}

Berbeda dengan maksim kesimpatian ini, diharapkan agar perserta tutur dapat memaksimalkan sikap simpati antara pihak yang satu dengan yang pihak yang lain. Sikap antipasti terhadap seseorang perserta tutur akan dianggap sebagai tindakan tidak santun. Kesimpatisan terhadap pihak lain dapat ditunjukan dengan sikap senyum, anggukan, gandengan tangan, dan sebagainya. Wijana (2011: 137) menyatakan bahwa "Maksim kesimpatian minimalkan 
ketidaksimpatian pada orang lain dan maksimalkan kesimpatian pada orang lain".

\section{Data [1]}

Kia : Sabar ya, ini cobaan buat kamu dan kelurgamu, aku cuma bisa berdoa semoga keluarga mu cepat diangkat dari penyakitnya.

Pada kutipan di atas siswa yang bernama Lia bercerita kepada temannya yang bernama Kia bahwa keluarganya ada yang sakit, akibat kecelakaan pada sore kemarin. Kia pun mendengarnya sangat kaget dan berusaha mengungkapkan rasa simpatinya kepada temannya yang bernama Lia. Tuturan di atas sangat jelas bahwa apa yang di tuturkan oleh temannya yang bernama Kia terindikasi mematuhi maksim kesimpatian, karena telah mengurangi antipati diri sendiri dengan orang lain. kutipan yang menyatakan bahwa Kia mematuhi maksim kesimpatian ialah: "Sabar ya, ini cobaan buat kamu dan keluagamu, aku cuma bisa berdoa semoga keluarga mu cepat diangkat dari penyakitnya”. Tuturan itu disampaikan dengan maksud bahwa ia memiliki rasa simpati terhadap keluarga Lia yang sedang mengalami musibah.

\section{Data [2]}

Bela : Iya disimpang mana, syukur kamu tidak apa-apa.

Data di atas dituturkan oleh siswa yang bernama Siska kepada temannya bernama Bela. Pada saat itu, ada seorang siswa yang bernama Lia memberitahukan temannya bahwa di jalan ada kejadian tabrak lari. Pada saat itu juga siswa yang bernama Bela kaget mendengarnya dan mengungkapkan rasa simpatinya. Tuturan di atas siswa yang bernama Bela terindikasi mematuhi maksim kesimpatian, karena telah mengurangi antipati diri sendiri dengan orang lain. Tuturan yang menyatakan bahwa Bela mematuhi maksim kesimpatian ialah: "Iya disimpang mana, syukur kamu tidak apaapa". Tuturan itu disampaikan dengan maksud, bahwa ia memiliki rasa simpati terhadap kakek tersebut. 


\section{SIMPULAN}

Berdasarkan hasil penelitian yang peneliti lakukan yaitu mengenai prinsip kesantunan berbahasa pada siswa SMP Negeri 1 Sungai Raya, dapat disimpulkan bahwa di lingkungan sekolah SMP Negeri 1 Sungai Raya terdapat prinsip kesantunan yang terdiri atas enam maksim yaitu, maksim kebijaksanaan, maksim kedermawanan, maksim penghargaan, maksim serderhanaan, maksim permufakatan, dan maksim kesimpatian.

Adapun simpulan secara khusus yaitu (1) data pada maksim kebijakasanaan pada tuturan siswa SMP Negeri 1 Sungai Raya sebanyak 13 data. Setiap data memiliki tuturan yang sopan terhadap lawan tutur maksim kebijaksanaan karena kurangi kerugian orang lain tambahkan keuntungan orang lain. (2) Data pada maksim kedermawanan pada pertuturan siswa SMP Negeri 1 Sungai Raya sebanyak 10 data. Setiap data memiliki tuturan yang sopan karena kurangi kentungan diri sendiri dan tambahi pengorbanan diri sendiri. (3) Data pada maksim penghargaan pada pertuturan siswa SMP Negeri 1 Sungai Raya sebanyak 10 data. Setiap data memiliki tuturan yang sopan karena kurangi cacian orang lain tambahi pujian terhadap orang lain. (4) Data pada maksim keserderhanaan pada pertuturan siswa SMP Negeri 1 Sungai Raya sebanyak 10 data. Setiap data memiliki tuturan yang sopan karena kurangi pujian terhadap diri sendiri dan tambahi cacian terhadap diri sendiri. (5) Data pada maksim permufakatan pada pertuturan siswa SMP Negeri 1 Sungai Raya sebanyak 10 data. Setiap data memiliki tuturan yang sopan karena kurangi ketidak sesuaian antar diri sendiri terhadap orang lain dan tingkatkan kesesuai antar diri sendiri terhadap orang lain. (6) Data pada maksim kesimpatian pada pertuturan siswa SMP Negeri 1 Sungai Raya sebanyak 4 data. Setiap data memiliki tuturan yang sopan karena kurangi antipati terhadap diri sendiri dengan orang lain dan tingkatkan simpati antar diri sendiri dengan orang lain. 


\section{DAFTAR PUSTAKA}

Dardjowidjojo, S. (2010). Psikolinguistik. Jakarta: Yayasan Pustaka Obor Indonesia

Darmadi, H. (2011). Metode Penelitian Pendidikan. Bandung: Alfabeta

Darmiati. (2014). Maksim Kesantunan Bahasa Dayak Bayadu Kecamatan Banyuke Hulu. Pontianak : Tidak Diterbitkan

Dimyati., \& Mudjiono. (2010). Belajaran dan pembelajaran. Jakarta: PT Ribeka Cipta

Leech, G. (2015). Prinsip-Prinsip Pragmatik. Jakarta: Universitas Indonesia

Lubis, H, H. (2011). Analisis wacana pragmatik. Bandung Angkasa

Mahsun. (2014). Metode Penelitian Bahasa. Jakarta: Rajawali Pers

Moleong, J, L. (2014). Metodologi penelitian Kualitatif. Bandung: PT Remaja Rosdakarya.

Nisa, F. (2016). Pelanggaran Prinsip Kesantunan Dalam Wacana Tutur Basuki Tjahaja Purnama (Ahok). Jurnal Penelitian Bahasa Sastra Indonesia dan Pengajarannya. 1 (1), 19.

Nurjamily, W, O. ( 2015). Kesantunan Berbahasa Indonesia Dalam Lingkungan Keluarga (Kajian Sosiopragmatik). Jurnal Penelitian Bahasa Sastra Indonesia dan Pengajaran. 3 (5), 11-13.

Putrayasa, I, B. (2014). Pragmatik. Yogyakarta : Graha Ilmu.

Rahardi, K. (2005). Pragmatik Kesantunan Imperatif Bahasa Indonesia. Jakarta Erlangga

Rohmadi, M., dkk. (2002). Belajar Bahasa Indonesia. Cekrawala Indonesia

Rohmadi, M. (2010). Pragmatik Teori dan Analisis . Surakarta: Yuma Pustaka.

Sholeha, S. (2016). “Analisis Prinsip Kesantunan Pada Novel Ranah Tiga Warna Karya Ahmad Faudi Kajian Sosioprgmatik”. Pontianak: IKIP PGRI

Subroto, E. (2011). Pengantar Studi Semantik dan Pragmatik. Cekrawala

Sugiyono. (2017). Metodologi Penelitian Pendidikan. Bandung:Alfabeta

Sujarweni, W. (2014). Metodologi Penelitian. Yogyakarta: Pustaka Baru Press 
Sulistyo, E, T. (2013). Pragmatik Suatu Kajian Awal. Surakarta: UNS Press

Supriyadi, S. (2011). Wacana Karikatur Indonesia. Surakarta: UNS Press

Tarigan, H, G. (2015). Pengajaran Pragmatik. Bandung: CV Angkasa.

Wijana., \& R. (2011). Analisis Wacana Pragmatik. Surakata: Yuma Pustaka

Yule, G. (2014). Pragmatik. Yogyakarta: Pustaka Pelajar.

Zuldafrial., \& Lahir. (2009). Pendekatan Penelitian dan Teknik Penulisan Karya Ilmiah. Pontianak: Pustaka Abuya. 